DOCTRINA

\title{
El delito de financiamiento del terrorismo en la legislación chilena
}

\author{
The offence of financing of terrorism in the Chilean legislation
}

\section{Edison CARrasco Jiménez}

Universidad Andrés Bello, Chile

\begin{abstract}
RESUMEN Este artículo tiene por objeto hacer un sucinto estudio del delito de financiamiento del terrorismo en Chile, revisando la legislación atingente tanto respecto de las personas naturales (artículo 8 de la Ley 18.314), como para el caso de las personas jurídicas (Ley 20.393). Se expone el contexto histórico-legislativo en el que fue introducido el delito en comento, junto con analizar en adición el fenómeno del financiamiento del terrorismo en el mundo. Luego se procede a efectuar un análisis dogmático de la figura delictiva en Chile, realizando algunas observaciones críticas en su caso sobre algunos puntos específicos de la legislación atingente.
\end{abstract}

PALABRAS CLAVE Delito de financiamiento del terrorismo, fenómenos del financiamiento del terrorismo, terrorismo, Ley 18.314.

ABSTRACT The article aims to make a succinct study of the crime of terrorism financing in Chile, reviewing the legislation affecting both natural persons (Article 8 of Law 18.314) and legal entities (Law 20.393). In addition, we do a study of the historical-legislative context in which the crime was introduced, together with an analysis of the phenomenon of the terrorism financing in the world. Then a dogmatic analysis of the criminal figure in Chile is carried out, making some critical observations in his case, on some specific points of the legislation about of the crime of terrorism financing.

KEYWORDS Crime of terrorism financing, terrorism financing case, terrorism, Act 18.314 . 


\section{Contexto de la legislación nacional sobre el financiamiento del terrorismo}

La inclusión de la figura del financiamiento del terrorismo en la legislación chilena se debe, principalmente, a los ataques que se produjeron en las Torres Gemelas en Nueva York el 11 de septiembre del 2001, ${ }^{1}$ hecho que generó una serie de legislaciones a nivel interno en Estados Unidos, como también a nivel internacional. La figura cobró importancia a raíz de estos hechos (Passas y Giménez-Salinas Framis, 2007: 494), probablemente por haber sido «percibidos $[. .$.$] como un fenómeno cualitativamente$ más grave y amenazante» (Zalaquett, 2006: 180).

El tema ya había sido abordado anteriormente en la Resolución 51/210 de la Asamblea General de las Naciones Unidas, del 17 de diciembre de 1996, y luego, con la adopción del Convenio Internacional para la Represión de la Financiación del Terrorismo» del 9 de diciembre de 1999.

Posteriormente, surge la Resolución 1.373 del 28 de septiembre de 2001 del Consejo de Seguridad de las Naciones Unidas, la cual declara expresamente dicho evento como punto de arranque, «reafirmando también su condena inequívoca de los ataques terroristas ocurridos en Nueva York, Washington D.C., y Pennsylvania el 11 de septiembre de 2001, y expresando su determinación de prevenir todos los actos de esa índole».

Ello repercutió de un modo u otro en las legislaciones internas de algunos países miembros de la ONU, como en el caso de Chile, con miras a la incorporación del financiamiento del terrorismo y de los principios de dichos instrumentos en sus ordenamientos jurídicos.

De ahí que el Estado de Chile haya suscrito el Convenio Internacional para la Represión de la Financiación del Terrorismo el 2 de mayo del 2001, pero además lo promulgó como ley de la República el 23 de julio del 2002, a través del Decreto 163/2002 del Ministerio de Relaciones Exteriores.

Fuera de ello, la figura específica del financiamiento del terrorismo se introduce en nuestra legislación a través de la Ley 19.906 del 13 de noviembre del 2003, la que modifica el antiguo texto del artículo 8 de la Ley 18.314 que «determina conductas terroristas y fija su penalidad», incorporando una disposición nueva relativa al fenómeno señalado. Esta Ley 19.906 lleva como encabezado un título bastante aclaratorio, refrendando lo que hemos expresado hasta ahora: «modifica la Ley 18.314 sobre conductas terroristas, en orden a sancionar más eficazmente la financiación del terrorismo, en conformidad a lo dispuesto por el Convenio Internacional para la Represión de la Financiación del Terrorismo».

El objetivo de la Ley 19.906, fue descrito en la historia de su constitución:

1. Cuestión que se señala expresamente en el Mensaje de la Ley 19.906 (Biblioteca del Congreso Nacional, 2007: 4). 
[S] observa con preocupación que el número y la gravedad de los actos terroristas dependen de la financiación del mismo. Dicha actividad constituye un factor determinante de los caracteres y consecuencias del terrorismo. Se comprende, entonces, la importancia de reforzar nuestra actual legislación penal mediante la incorporación de un tipo penal que cubra aquellas hipótesis de financiación que, de otra forma, podrían quedar impunes (Biblioteca del Congreso Nacional, 2007: 3).

A grandes rasgos, el objetivo era incorporar de forma específica el financiamiento del terrorismo y sancionar los casos en que existiese una red de financiamiento de las actividades terroristas (Biblioteca del Congreso Nacional, 2007: 13). Esto pese a existir opiniones que consideraban que el financiamiento del terrorismo es una realidad mucho más alejada de Chile que el lavado de activos y el cohecho. ${ }^{2}$

Sin embargo, se expresó en el Mensaje de dicha Ley, que la regulación sería más bien austera, alejada del uso contemporáneo que se ha dado al derecho penal como un instrumento de control social de prima ratio, teniendo como objetivo único la «penalización de aquellas conductas que aparecen como intolerables para la convivencia humana», conducta que representaría el terrorismo (Biblioteca del Congreso Nacional, 2007: 4).

Con posterioridad a la ley anterior, se dicta la Ley 20.393, del 2 de diciembre del 2009, por la cual se establece la responsabilidad penal de las personas jurídicas en algunos delitos entre los que se cuenta el financiamiento del terrorismo.

\section{Marco legislativo}

\section{Normas básicas sobre el delito de financiamiento del terrorismo en Chile}

Es el artículo 8 de la Ley 18.314, el que trata sobre el financiamiento del terrorismo en Chile.

Tratándose de una persona jurídica, el artículo 1 de la Ley 20.393 que establece la responsabilidad de las personas jurídicas por algunos delitos, entre ellos, el financiamiento del terrorismo, nos reenvía al artículo 8 de la Ley 18.314 de 1984 que «determina conductas terroristas y fija su penalidad». En efecto, el artículo 1 de la ley citada señala: «La presente ley regula la responsabilidad penal de las personas jurídicas respecto de los delitos previstos en el [...] artículo 8 de la Ley 18.314».

Por lo demás, no puede dejar de considerarse a la Constitución Política de la República, que se refiere en específico al terrorismo en su artículo 9.

También debe señalarse el Convenio Internacional para la Represión de la Financiación del Terrorismo, promulgado en Chile por el Decreto 163/2002 del Ministerio

2. Opinión del abogado Ciro Colombara en los debates de la Ley 20.393 (Biblioteca del Congreso Nacional, 2017: 124). 
de Relaciones Exteriores el 23 de julio del 2002, e incorporado, por lo tanto, como legislación patria.

Igualmente habría que hacer mención, conforme a lo anteriormente expresado, a la Resolución 1373/2001 del Consejo de Seguridad de las Naciones Unidas y que el Mensaje de la Ley 19.906 expuso en su momento (Biblioteca del Congreso Nacional, 2007), aunque más bien como un antecedente de la ley y recomendación general.

Relación entre el Convenio como Ley de la República y el artículo 8 de la Ley 18.314

Si bien tanto el artículo 8 de la Ley 18.314, como el Convenio Internacional para la Represión de la Financiación del Terrorismo tratan el financiamiento del terrorismo, no se refieren al mismo objeto.

El Convenio, en estricto rigor, trata de la cooperación internacional entre Estados respecto al financiamiento del terrorismo, y no a una regulación interna del Estado. Esto quedó sentado en actas durante la aprobación de dicho Convenio ante el Congreso (cf. Congreso Nacional, 2001). Y aun el mismo Convenio en su artículo 3 lo deja suficientemente claro, al hacerlo inaplicable ante presuntos delincuentes nacionales en hechos cometidos en suelo nacional y siempre que exista exclusión de la jurisdicción de otro Estado. ${ }^{3}$

En cambio, la ley patria referida al financiamiento del terrorismo en Chile como figura delictiva y a sus nacionales como presuntos responsables, es el artículo 8 de la Ley 18.314, tratándose de personas naturales, y tratándose de personas jurídicas, aquélla complementariamente con la Ley 20.393.

Pero el hecho de que el Convenio esté más orientado hacia la cooperación internacional no implica que ése sea su uso exclusivo. De hecho, debiese ocuparse en materia interpretativa y como recurso para la interpretación sistemática, e incluso, teleológica, ya que se entiende que es ley, y bajo ese mismo rango habría de aplicarse en la interpretación de ley.

\section{Conceptos fundamentales}

\section{Concepto de terrorismo}

Elemento del concepto de terrorismo. Para López Calera (2002), las características que integrarían el concepto de terrorismo son: el que sea un atentado (acción humana)

3. «El presente Convenio no será aplicable cuando el delito se haya cometido en un solo Estado, el presunto delincuente sea nacional de ese Estado y se encuentre en el territorio de ese Estado y ningún otro Estado esté facultado para ejercer la jurisdicción con arreglo a lo dispuesto en el párrafo 102 del artículo 7 , con la excepción de que serán aplicables a esos casos, cuando corresponda, las disposiciones de los artículos 12 a $18 »$. 
contra los derechos fundamentales, que el atentado sea una violencia indiscriminada que se ejerce sobre una población y que produzca terror, que una generalidad de personas sienta ese terror, que ese terror sea relativamente permanente en el tiempo, y que los motivos políticos sean declarados.

Lamarca Pérez (2013: 43), en una inferencia dogmática, apunta a dos elementos: un elemento estructural, el que sería la pertenencia a una organización; y un elemento teleológico, el de subvertir el orden constitucional o alterar gravemente la paz pública.

En general, los autores describen como elementos las acciones o atentados violentos contra un orden político, que sean organizados y planificados desde la clandestinidad, reiterados en el tiempo, y con una finalidad de producir inseguridad y miedo. ${ }^{4}$

En Chile, Villegas Díaz (2016) define, antes que un concepto, los elementos que debieran estar presentes para que exista terrorismo (en el contexto de la legislación penal chilena) desde el punto de vista jurídico-penal: a) la finalidad política, en el sentido de alterar el orden constitucional; b) medios idóneos para causar terror, especialmente catastróficos; c) conductas que importen violencia grave, como atentados contra la vida, la integridad física, la libertad y la propiedad pública. El elemento determinante es, para la autora, la idoneidad del medio (2016: 167-168). Además, al elemento «alterar el orden constitucional» la autora le proporcionaría como fundamento la idea de un «régimen democrático amparado en la libre determinación de los pueblos» (2016: 167).

Estamos contestes con los elementos presentados por la autora, con algún matiz.

Legislaciones como la chilena tienen como paradigma la clásica visión del terrorismo de finalidad explícita, esto es, aquel que expresa su objetivo político. Sin embargo, una nueva forma de terrorismo se hizo visible durante la Guerra Fría - aunque el concepto sea antiguo- que es la del terrorismo de finalidad subyacente. No interesa la declaración de la finalidad, sino lo que interesa es que el efecto logrado con la actividad terrorista conduzca al fin político querido por el individuo y/o grupo, aunque ni la finalidad se explicite ni el grupo se haga visible. Es más seguro para el objetivo del plan convencer a otro que son sus propias decisiones, antes que decirle que cumpla con decisiones ajenas, ya que, en este caso, una decisión política injertada desde fuera siempre se mirará con resistencia e invitará constantemente a deshacerse. Pero es distinto el panorama si se cree que son las propias decisiones las que se adoptan. La actividad terrorista se vuelve más estratégica cuando, para lograr con su finalidad política, hace uso de cualquier medio. Con el terrorismo de los stay-behind, por ejemplo, se obtuvo durante un tiempo su verdadera finalidad política: el que se persiguiese política y criminalmente a la izquierda europea al atribuirle los hechos terroristas que tuvieron lugar en tiempos de la Europa Occidental de la Guerra Fría.

4. Véase Gaete González (2010), Morales (2012), Rivas Nieto (2013), Úbeda-Portugués (2008: 25) y Waldmann (2007: 62). En forma crítica, véase Leiva (2015) y Nievas (2015). 
Por ello que la idoneidad del medio para causar terror es un primer elemento. Pero igualmente se debe considerar cuál es la consecuencia política que se produciría con el ataque: ¿mayor control policial?, ¿anatemizar a un grupo específico?, ¿conducir a un pueblo a una guerra contra otro? Si ha de considerarse, como primer elemento objetivo, la idoneidad del medio para causar terror, luego debiera evaluarse, como segundo elemento objetivo, la idoneidad del terror para «arrancar» una determinada decisión política, que, de no existir, no se adoptaría o no se hubiese adoptado. Y cuando se habla de decisión política se está refiriendo a todos los campos decisorios del espectro: desde la conformación del Estado, hasta lo económico.

Un concepto «dogmático» de terrorismo. No existe en la legislación chilena un concepto de terrorismo. Como bien señala la doctrina, el concepto de terrorismo es bastante disputado, en general, por la vaguedad en la atribución de significados, cuestión que ha impedido ser precisado, tanto por la doctrina internacional —según ya comentamos anteriormente-, como por la nacional (Torres Vásquez, 2010; Villegas Díaz, 2006: 3; Villegas Díaz, 2016).

Desde la dogmática sería posible adelantar algún concepto. El artículo 9 inciso 1 de la Constitución de la República establece: «El terrorismo, en cualquiera de sus formas, es por esencia contrario a los derechos humanos».

Por su parte, el artículo 1 inciso 1 de la Ley 18.314, expresa:

Constituirán delitos terroristas los enumerados en el artículo 2, cuando el hecho se cometa con la finalidad de producir en la población o en una parte de ella el temor justificado de ser víctima de delitos de la misma especie, sea por la naturaleza y efectos de los medios empleados, sea por la evidencia de que obedece a un plan premeditado de atentar contra una categoría o grupo determinado de personas, sea porque se cometa para arrancar o inhibir resoluciones de la autoridad o imponerle exigencias.

El mismo artículo 1 nos reenvía necesariamente al artículo 2 conforme al cual se describen los delitos que constituirían, en conformidad al artículo 1, delitos terroristas, entre ellos, el homicidio, la castración, las lesiones menos graves y graves, secuestro y de sustracción de menores, incendio y estrago, atentados contra la salud pública, descarrilamiento, apoderamiento o atentado contra un medio de transporte público en servicio, utilización de armas de gran poder destructivo o de aniquilación, y atentados contra la vida o la integridad física de ciertos personeros en razón de su cargo.

Conforme a estas dos disposiciones, sería posible señalar que, para el ordenamiento jurídico, terrorismo habrían de ser los hechos que siendo por esencia contrarios a los derechos humanos, se realizan con la finalidad de producir en la población o en una parte de ella el temor justificado de ser víctima de delitos contra la vida, la integridad física y la libertad personal, por la realización de atentados contra ellas mismas o contra personeros con autoridad nacional o internacional. 


\section{Concepto de financiamiento del terrorismo}

En legislaciones como la española, el término utilizado es el de «financiación» y no «financiamiento», como en la legislación chilena, aunque en estricto rigor no hay diferencias importantes entre ambos términos. De cualquier manera, la Ley 19.906 que modificó justamente el artículo 8 de la Ley 18.314, utiliza en su encabezado el término «financiación», por lo que podría utilizarse este término indistintamente. Sin perjuicio de esta puntualización meramente terminológica, nosotros nos inclinamos de todos modos por aquél que utiliza la última ley relativa a la materia, la Ley 20.393, esto es, «financiamiento».

Siendo así, podemos decir que el Diccionario de la lengua española define el financiamiento como la «acción y efecto de financiar», y «financiar», como «1. Aportar el dinero necesario para una empresa. 2. Sufragar los gastos de una actividad, de una obra, etcétera».

En el caso específico de la persona jurídica, el financiamiento del terrorismo implicaría que la persona jurídica esté destinando parte de su activo a sufragar los gastos de actividades terroristas.

Nuestra legislación, en específico el artículo 8 de la Ley 18.314, nos señalaría en qué consiste este financiamiento. Así, en la citada norma, se expresa que se castigaría «el que por cualquier medio, directa o indirectamente, solicite, recaude o provea fondos con la finalidad de que se utilicen en la comisión de cualquiera de los delitos terroristas señalados en el artículo 2».

Siendo así, se podría inferir de la legislación chilena un concepto de financiamiento del terrorismo por persona jurídica, consistente en la solicitud, recaudación o la provisión de fondos por parte de una persona jurídica, con la finalidad de que se utilicen en la comisión de cualquiera de los delitos terroristas señalados en el artículo 2 de la Ley 18.314 .

«Atribución de responsabilidad penal» de la persona jurídica en el delito de financiamiento del terrorismo, sus problemas y realidades en Chile

Según y como ya se ha apreciado precedentemente, si bien el artículo 1 de la Ley 20.393 es el que señala los delitos respecto de los cuales procede imputar una responsabilidad penal de la persona jurídica, entre ellos, el financiamiento del terrorismo, es el artículo 3 el que determina la responsabilidad penal de la persona jurídica.

En este punto se producen algunas paradojas importantes al tratar el financiamiento del terrorismo. En primer lugar, el artículo 3 de la ley citada requiere, para la atribución de responsabilidad penal, que los actos «fueren cometidos [...] en su interés o para su provecho». Ya en doctrina no se advierte un beneficio económico a 
obtener por la persona jurídica en la comisión de este delito. ${ }^{5}$ Tampoco se aprecia por nosotros. Dicho de otro modo, ¿cuál es la ventaja económica?

Ahora, comprendamos las expresiones anteriores no como interés o provecho económico inmediato, sino como un beneficio a largo plazo. Tal vez podría ocurrir en situaciones en las que una persona jurídica pueda beneficiarse con la toma del poder político estatal por facciones terroristas, que ella financia, y que luego, hechos del poder las tales facciones terroristas, concedan beneficios económicos a la persona jurídica que los financió, como ventajas monopólicas, exenciones tributarias, etcétera. Pero para poder perseguir criminalmente a la persona jurídica por este motivo tendría que existir un régimen de garantías que permita hacerla responsable, cosa que sólo podría producirse de fracasar la facción terrorista en la toma del poder. Esto ya supondría restringir al máximo las posibilidades de responsabilizar penalmente a una persona jurídica.

En segundo lugar, si gran parte de esta responsabilidad se asienta en la idea del defecto de organización, lo que conduce a que la persona jurídica sea responsable penalmente solo si no incorporara a su estructura un modelo de prevención de delitos, según como señala el inciso 3 del artículo 3 y el artículo 4, y como lo deja establecido la historia de la Ley 20.393 (Biblioteca del Congreso Nacional, 2017: 145), se reduce dicha responsabilidad a un mínimo. Prácticamente la persona jurídica sería penalmente responsable solo si fuese una tapadera para el financiamiento de la actividad terrorista.

En tercer lugar, si ya el terrorismo como fenómeno general en Chile presenta una realidad exigua para las personas naturales, siendo un delito más bien marginal en comparación con otros delitos, el financiamiento del terrorismo de la persona jurídica, en los términos en que se encuentran redactadas las leyes sobre terrorismo, es hoy casi inexistente.

En cuarto lugar, la orientación de los instrumentos internacionales es a la sanción de entidades que financian actividades terroristas de organizaciones que actúan transnacionalmente, cuestión que no parece representar la realidad país.

Conforme con este panorama, la Ley 20.393 responde más bien a dar cumplimiento a los instrumentos internacionales sobre responsabilidad de las entidades en el financiamiento del terrorismo, pero no estaría respondiendo, a nuestro juicio, a una realidad social, puesto que no se hace cargo. Así, y en este espacio delictual delimitado, esta normativa se convierte más en derecho penal simbólico, que en un derecho penal necesario y efectivo.

5. Opinión del abogado del Instituto Libertad y Desarrollo, Axel Buchheister en los debates de la Ley 20.393 (Biblioteca del Congreso Nacional, 2017: 130). 
Particularidades del delito de financiamiento del terrorismo por la persona jurídica

\section{Clasificación del delito de financiamiento del terrorismo}

a) Es un delito y/o tipo autónomo. Así, al menos, fue concebido, según el Mensaje de la Ley 19.906 (Biblioteca del Congreso Nacional, 200: 4) ${ }^{6}$ y como es entendido en general para el delito prescrito en el Convenio (Fondo Monetario Internacional, 2003: 19).

b) Es un delito de mera actividad. Esto sería así ya que se agota en la realización de la conducta, sin la necesidad de resultado ulterior. Por ende, este delito se agota en la «solicitud», «recaudación» y en la "provisión» de fondos, sin necesidad de que se haya concretado o no el delito terrorista, por ende, hecho efectivo los fondos.

En efecto, el Convenio, que por lo demás es ley de la República conforme al decreto 163/2002, en su artículo 2.3, según ya pudimos revisar, entiende esto mismo al prescribir: «Para que un acto constituya un delito [terrorista], no será necesario que los fondos se hayan usado efectivamente para cometer un delito [terrorista]».

También de este mismo modo fue entendido en las discusiones de la Ley 19.906. Primero, al ser señalado de este modo en las discusiones de la ley por Juan Bustos (Biblioteca del Congreso Nacional, 2007: 48); segundo, al tratar el tema de la cláusula de subsidiariedad expresa, como se verá más adelante.

Según el FMI, habría de ser de un delito de mera actividad, porque el financiamiento del terrorismo es distinto de un delito de asistencia o incitación a la comisión de actos terroristas, o asociación para cometer ese tipo de actos (Fondo Monetario Internacional, 2003: 52-53).

En el derecho comparado también ha sido entendido de este modo, en algunos casos por la doctrina (Oficina de las Naciones Unidas contra la Droga y el Delito. Colombia, 2014: 132) y, en otros, se infiere de la misma legislación, como del Código Penal español, donde se tipifica la conducta del financiamiento del terrorismo (artículo 576.1), y se mantiene una figura de agravación separada y distinta de la conducta típica nuclear, si los bienes o valores se pusieran efectivamente a disposición del responsable del delito de terrorismo (artículo 576.2, primera parte), y en otra figura también distinta y separada, se castiga a título de coautoría o complicidad, si los bienes o valores llegaran a ser empleados para la ejecución de actos terroristas concretos (artículo 576.2, segunda parte), lo que en los hechos representaría una agravación de la responsabilidad penal. En estos últimos casos, existe una intensificación del reproche, pero en razón del resultado; por lo que, no existiendo ambos resultados, queda la figura nuclear, que representa el delito de mera actividad.

6. En la legislación peruana, el carácter de autónomo se reconoce en un tipo semejante al chileno, en forma expresa en el artículo 2 de la Ley 25.475. 
c) Es un delito mutilado en dos actos. Que se prueba con la existencia del elemento subjetivo en el tipo penal específico, el cual declara la finalidad, y que expresa la intención en la realización de un acto posterior, como la actividad terrorista, pese a satisfacerse con la sola conducta del financiamiento.

Así fue interpretado por la doctrina española antes de la Reforma del 2015, frente a un tipo penal semejante al chileno (cf. González Cussacy Vidales Rodríguez, 2009: 197).

d) Es un tipo mixto cumulativo. Entendemos que el tipo del financiamiento del terrorismo básicamente correspondería a lo que la doctrina alemana y española denominan como tipos mixtos cumulativos, ya que las conductas de «solicitar», «recaudar», "proveer», no son modalidades de un mismo delito, sino que son tipos distintos, respondiendo cada uno a su propio dolo, y no al dolo común de un delito, como sí lo sería un tipo mixto alternativo. ${ }^{7}$

Lo dicho se refuerza con dos cuestiones: a) el hecho de que la cláusula de subsidiariedad sea aplicada sólo a la "provisión», y no a las otras conductas; b) la conducta de «solicitar» puede ser efectuada por el mismo que realice una actividad terrorista, no así la provisión.

Si se diesen las tres conductas en un mismo hecho por un mismo sujeto, se daría entonces un concurso de delito, y no un posible concurso aparente de leyes penales, como habría de ocurrir en el caso de un tipo mixto alternativo.

\section{Bien jurídico probable comprometido en el delito}

En Chile, algunos opinan que el bien jurídico en el financiamiento es el mismo que para el caso del delito terrorista, esto es, bienes singulares, como la vida, la integridad física y la libertad, y bienes colectivos, como la seguridad pública y la seguridad interior del Estado (Plaza Chávez, 2015: 181).

En doctrina comparada, también se entiende como bien jurídico a la seguridad pública (Oficina de las Naciones Unidas contra la Droga y el Delito, 2014: 123-124).

Conforme al Mensaje de la Ley 19.906, que es la que introduce el actual artículo 8 de la Ley 18.314, si teniendo a la vista para la introducción de este artículo que el terrorismo constituye «un atentado severo contra la paz, condición imprescindible para la vida en sociedad», y que «se observa con preocupación que el número y la gravedad de los actos terroristas dependen de la financiación del mismo» (Biblioteca del Congreso Nacional, 2007: 3), entonces, si la paz es condición para la vida en sociedad y este significado ha de entenderse como contenido del concepto «seguridad pública», podríamos entender que uno de los bienes jurídicos afectados por el financiamiento del terrorismo es la seguridad pública.

7. Para el tipo mixto cumulativo, véase Binding (1918: vol. I, 206); Binding (1918: vol. II, 931 y ss.). Para tipo mixto alternativo, Hiller (1880: 228-230). 
En cuanto a los bienes jurídicos como la vida o la integridad física, en tanto bienes jurídicos individuales — y dado que el Mensaje de la Ley 19.906 estima que «el terrorismo degrada al hombre, tanto a las víctimas como a los victimarios»-, igualmente debiesen ser considerados. Sin embargo, y en virtud de que se trata de un delito de mera actividad, habría de constituirse el financiamiento del terrorismo como un delito de peligro abstracto.

\section{Tipo penal del delito de financiamiento del terrorismo}

\section{Conducta típica}

La conducta típica estaría precisada en el artículo 8 de la Ley 18.314, el cual, y como ya fue expresado, castigaría al «que por cualquier medio, directa o indirectamente, solicite, recaude o provea fondos con la finalidad de que se utilicen en la comisión de cualquiera de los delitos terroristas señalados en el artículo 2».

Esta disposición tiene similitudes evidentes con el artículo 2.1 del Convenio, el que señala los actos a los que tendría que estar intencionado el financiamiento.

En cuanto a los delitos y/o actos determinados, y que son objeto del financiamiento, es entendido por ambos preceptos (artículo 8 de la Ley 18.314 y artículo 2.1 del Convenio) el carácter de terroristas, para darle contenido a la definición de «terroristas», mediante la enumeración de ciertos actos específicos y/o mediante la mención de características generales de lo que debiese ser un acto terrorista.

Tratándose del Convenio, el artículo 2.1 utiliza un criterio formal (artículo 2.1 letra a), ${ }^{8}$ y un criterio material (artículo 2.1 letra b). ${ }^{9}$

El artículo 8 de la Ley 18.314 nos remite, para la definición de esos actos, al artículo 2. Pero no basta el artículo 2 con su catálogo de delitos, ya que falta lo establecido en el artículo 1 («Constituirán delitos terroristas, cuando cumplieren lo dispuesto en el artículo anterior»), con lo cual hay una doble remisión o remisión derivada, para conocer recién dichos actos: «la finalidad de producir en la población o en una parte de ella el temor justificado de ser víctima de delitos de la misma especie, sea por la naturaleza y efectos de los medios empleados, sea por la evidencia de que obedece a un plan premeditado de atentar contra una categoría o grupo determinado de personas, sea porque se cometa para arrancar o inhibir resoluciones de la autoridad o imponerle exigencias». Este sería el fin del elemento intencional, el mismo señalado en la

8. «Un acto que constituya un delito comprendido en el ámbito de uno de los tratados enumerados en el anexo y tal como esté definido en ese tratado».

9. «Cualquier otro acto destinado a causar la muerte o lesiones corporales graves a un civil o a cualquier otra persona que no participe directamente en las hostilidades en una situación de conflicto armado, cuando, el propósito de dicho acto, por su naturaleza o contexto, sea intimidar a una población u obligar a un gobierno o a una organización internacional a realizar un acto o a abstenerse de hacerlo». 
Convención, y podríamos decir que no existe gran diferencia entre uno y otro caso, ya que lo que señala la Convención es más sintético que lo prescrito en el artículo 8 , pero la referencia es similar, al hablar de «acto destinado» $\mathrm{o}$ "propósito».

La expresión del artículo 8 «por cualquier medio» supondría, en primer lugar, que el tipo de financiamiento, fuese legal o ilegítimo, quedaría cubierto por el tipo; en segundo lugar, que los medios por los cuales la conducta se manifiesta fuesen cualesquiera. Así, si es para solicitar fondos, cualquier medio debe considerarse (personalmente, telefónicamente, por medios electrónicos, etcétera); o cualquier medio para recaudarlos (recepción física, beneficios, aportes, etcétera), o bien, cualquier medio para proveerlos (a través de entrega física de dinero, por transferencia electrónica, por criptodivisa o bitcoins, mediante especies, prestaciones, etcétera). La expresión del Convenio "por el medio que fuere», no es distinta a la anterior.

Por su parte, la expresión «directa o indirectamente» es idéntica a la del Convenio (artículo 2.1), y debiera entenderse en casos en que el financiamiento se solicita de forma personal, como si se hiciera también por un intermediario (Commonwealth Secretariat, 2002: 268).

Los verbos rectores contemplarían a su vez, tres clases de conductas diferentes. La primera es la de «solicitar», esto es, que se castigaría por este artículo al que pide fondos para financiar el terrorismo. Conforme al significado otorgado por el Diccionario de la lengua española al verbo «solicitar», sería: «1. Pretender, pedir o buscar algo con diligencia y cuidado. 2. Hacer diligencias o gestionar los negocios propios o ajenos». Esta conducta típica en el financiamiento del terrorismo no tiene parangón en la legislación comparada, ${ }^{10}$ salvo en Estados Unidos y con la introducción de la Patriotic Act 2001, Sección 411 (4), donde sí se incorpora el «solicitar» («solicit funds or other things») como conducta típica.

Este término fue intensamente discutido en el Congreso, se eliminó en los debates en el Senado y fue repuesto por la Comisión Mixta, en el entendido que su objetivo era «anticipar la punibilidad en el caso de la recaudación, a fin de sancionarla aun si materialmente los dineros no llegan a poder del recaudador». En su momento, Waldo del Villar defendió la inclusión del término en similar sentido de la anticipación de la punibilidad, ejemplificando el caso en que «quien desee colaborar con la causa terrorista invite y solicite, veladamente, ayuda para la misma, sin recaudar dichos fondos, operación que debía ser cubierta por un tercero». Para Rodrigo Medina Jara, invitado a los debates, formas verbales como la de «solicitar» adelantaban peligrosamente la consumación a límites intolerables. De considerar el elemento subjetivo de intención trascendente que se contemplaba en la norma original del Ejecutivo, implicaría un

10. La Ley 26.268/2007 en Argentina, que modificó su Código Penal introduciendo el artículo 213 quáter, sólo hace uso de dos conductas, la de «recolección» y la de "provisión». El Decreto Ley 25.475 de Perú, en su artículo 4.A, señala a la «provisión», al «aporte» y la «recolección». 
doble adelantamiento. Por otro lado, el verbo «recaudar» contemplaría ya como significado el de «solicitar». Para Francisco Maldonado, si «recaudar» se podía entender como un acto preparatorio de la financiación, «solicitar» sería una «tentativa del acto preparatorio de la financiación», por lo que estima su consignación como inadmisible, ya que la solicitud sería castigada como tentativa, según el artículo 7 de la Ley 18.314, con la misma pena que el financiamiento con la exclusión del grado, es decir, una tentativa castigada en grado de consumado. Ello podría dar lugar a situaciones extremas, como «castigar a alguien que llama por teléfono para pedir financiamiento terrorista y que no logra dar el mensaje porque se interrumpe la comunicación», y a una nula incidencia práctica del verbo «solicitar» (Congreso Nacional, 2003b: 4-6).

Pese a estos argumentos, Bustos consideró que «solicitar» describía una conducta independiente. Así como en el cohecho, la solicitud es independiente de la recepción del beneficio económico, lo mismo en este caso, entendiendo un error que fuese la tentativa de un acto preparatorio regido por el artículo 7 de la Ley 18.314, puesto que es un delito de mera actividad, sin ser relevante si se da o no el dinero solicitado. Finalmente, la Comisión Mixta decidió incorporar dicho verbo rector (Congreso Nacional, 2003b: 6).

La doctrina nacional ha entendido, en general, que la solicitud sí es un acto preparatorio a la recaudación y, por ende, no debiera haberse recogido en el tipo penal (Plaza Chávez, 2015: 184). Ahora bien, la conducta de «solicitar» bien puede ser desplegada por quien haya de realizar una actividad terrorista, y que necesite fondos para realizarla, como aquél que pide para otro. Por eso parece ser más una conducta independiente de la recaudación y de la provisión.

La segunda es el «recaudar», esto es según el Diccionario de la lengua española: «1. Cobrar o percibir dinero. 2. Asegurar, poner o tener en custodia, guardar». En suma, la obtención y guarda de los fondos para el financiamiento. Villegas Díaz no está de acuerdo con la inclusión de esta conducta, tanto porque en el propio Mensaje del Proyecto de la Ley 19.906 señalaba que el que recaudaba fondos no le cabe responsabilidad en delito terrorista alguno, como por el sentido natural y obvio del término (2006: 23).

En contraposición a la anterior afirmación, se encuentra la opinión de Plaza Chávez, quien señala que la frase del Mensaje en que se señalaba lo anterior, estaría sacada de contexto, ya que es usada para ilustrar que en la cláusula de subsidiariedad expresa se refiere sólo a la provisión, y no a la recaudación. El autor, además, hace una referencia al texto del Mensaje presuntamente sacado de contexto, en una nota al pie (2015: 185).

No sabemos a ciencia cierta cuál es el texto que Villegas Díaz considera para afirmar su postura, ya que, en principio, no señala ninguno. Estimamos que tal vez pueda ser el siguiente: «En síntesis, se advierte que el financiamiento terrorista resulta punible sólo en cuanto la provisión de fondos pueda vincularse a un delito terrorista específico (consumado, tentado o a título de conspiración) o a una asociación ilícita terrorista. Por otra parte, se comprende que en ambas hipótesis se requiere un fi- 
nanciamiento efectivo, esto es, provisión o entrega de fondos. La mera recolección o recaudación de fondos no resultaría, en principio, punible» (Biblioteca del Congreso Nacional, 2007: 4). Pero esta referencia es al estado de la legislación al día de la propuesta de la Ley: se queja justamente de que cubre imperfectamente las conductas de provisión y de recaudación. Por eso, «el tipo penal que aquí se propone asume ambos aspectos, cubriendo así todo el espectro de conductas asimilables a financiamiento terrorista» (el énfasis es nuestro). Y por ello, $\mathrm{y}$ «para resolver el segundo aspecto, se decidió ampliar el tipo autónomo propuesto también a la mera recaudación de los fondos para la comisión de delitos terroristas» (Biblioteca del Congreso Nacional, 2007: 4-5; el énfasis es nuestro). El Mensaje de la Ley parece ser bastante claro en incorporar la recaudación como conducta típica.

La tercera conducta es la de «proveer» que, conforme a las dos acepciones más cercanas al concepto, sería, según el Diccionario de la lengua española, la de «2. Suministrar o facilitar lo necesario o conveniente para un fin. 3. Tramitar, resolver, dar salida a un negocio». Esto es, dotar de recursos económicos. También el facilitar las llaves de un depósito de armas (Plaza Chávez, 2015: 185).

Conforme a ello, se castigarían tres conductas: el pedir, el recaudar y el dar financiamiento para actividades terroristas. Con lo cual se pretendería cubrir tres conductas diferentes bajo un solo tipo penal, como lo sería el financiamiento del terrorismo, unidas por su relación con la materia de la que trataría el tipo penal, más que por ser modalidades de una misma conducta; en estricto rigor, no lo son.

Recordemos que el Convenio, por su parte, en su artículo 2.1, sólo se refiere al que «provea o recolecte», con lo que estaría excluyendo al solicitante.

\section{La voz «fondo» y sus características}

El comentado artículo 8 de la Ley 18.314 utiliza la expresión «fondos», ${ }^{11}$ la que integra el tipo penal.

El Convenio entiende por fondo «los bienes de cualquier tipo, tangibles o intangibles, muebles o inmuebles, con independencia de cómo se hubieran obtenido, y los documentos o instrumentos legales, sea cual fuere su forma, incluida la forma electrónica o digital, que acrediten la propiedad u otros derechos sobre dichos bienes incluidos, sin que la enumeración sea exhaustiva, créditos bancarios, cheques de viajero, cheques bancarios, giros, acciones, títulos, obligaciones, letras de cambio y cartas de crédito» (artículo 1 número 1). ${ }^{12}$

11. El Código Penal argentino, en su artículo 213 quáter, prefiere utilizar la expresión «bienes o dinero». El Decreto Ley 25.475 de Perú, en su artículo 4.A, usa una expresión mucho más extensa, al señalar por objeto «fondos, recursos financieros o económicos o servicios financieros o servicios conexos».

12. El Fondo Monetario Internacional señala que la Resolución 1.373/2001 tendría una amplitud mayor para la definición de fondos que el Convenio, al incorporar «cualesquiera fondos, recursos finan- 
En este mismo sentido, en la Historia de la Ley 19.906 se dejó expresa constancia que dicho término haría referencia no sólo al dinero, sino igualmente a otros bienes, como, por ejemplo, autos, casas o armas, que pudieren ser solicitadas, recaudadas y provistas (Biblioteca del Congreso Nacional, 2007: 17). Sin embargo, este sentido queda un tanto enturbiado en las discusiones ante el Senado, cuestión que, a nuestro juicio, no afecta el sentido anterior acerca del término «fondos». ${ }^{13}$ Según el modo anterior es expresado también por la doctrina chilena (Plaza Chávez, 2015: 173).

Por ende, pareciera entenderse el término «fondos» en el sentido más amplio posible, como cualquier recurso que represente un activo de beneficio para la actividad terrorista ${ }^{14} \mathrm{y}$ con independencia del medio empleado. ${ }^{15}$

Sin embargo, esta amplitud es criticada en la interpretación del Convenio por su colisión con la taxatividad penal (González Cussac y Vidales Rodríguez, 2009: 185-186).

En efecto, por el término «fondos» podrían colarse una serie de formas que quizás no necesariamente puedan incluirse, tal y como pasa actualmente en la interpretación del término «apoyo material o recursos» («material support or resources») en la Patriotic Act 2001 de Estados Unidos, según como se expresó en el apartado pertinente a la legislación comparada. La ley pareciese no comprender la capacitación como forma de financiamiento (que se ha entendido que el Convenio, tampoco lo

cieros o económicos o servicios financieros o servicios conexos de otra índole» (1.d). Pero el Convenio sólo es diferente en los términos formales, ya que le da completa amplitud a su definición de «fondo». De hecho, utiliza la expresión «sin que la enumeración sea exhaustiva», por lo que indica un numerus apertus, y una inclusión de todo tipo de forma de fondo. Cf. Fondo Monetario Internacional, 2003: 46. El Commonwealth Secretariat señala que los fondos son activos de todo tipo, tangibles o intangibles, muebles o inmuebles, por cualquier medio adquirido, documentos legales o instrumentos en cualquier forma, incluyendo electrónicos o digitales, que demuestren título o interés en dichos activos, créditos bancarios, cheques de viaje, cheques bancarios, giros postales, acciones, valores, bonos, borradores y cartas de crédito (2006: 36).

13. En el seno del Senado se produjo una discusión en torno a si el significado del término incluía o no otros bienes que no fueran sólo dinero, solicitándose reemplazar el término por otros que sí significasen bienes u otros semejantes. Con esto queda un tanto ilustrado que el Senado o no lee las actas de la discusión anterior, o no es informado de ellas, puesto que, de haberlo sabido, ni siquiera se hubiese entrado en la discusión, con la eventual pérdida de tiempo que ello significase. Tampoco en esta discusión se hizo mención al significado que se otorga al término «fondos» por el Convenio Internacional para la Represión de la Financiación del Terrorismo. Por otro lado, impresiona el desconocimiento que tenía el entonces presidente de la Sala, Andrés Zaldívar, de que éste era un proyecto de ley nuevo del Ejecutivo, y no un convenio que se intentaba incorporar en la legislación patria. Cf. Biblioteca del Congreso Nacional (2007: 35-40).

14. Así se ha entendido también en otras legislaciones similares, como la del Código Penal colombiano. Cfr. Oficina de las Naciones Unidas contra la Droga y el Delito (2014: 128-129).

15. Referencia hecha a la «voz» fondos en la entonces legislación española (González Cussac y Vidales Rodríguez, 2009: 185). 
contemplaría; cf Oficina de las Naciones Unidas contra la Droga y el Delito, 2006: 14) y no podría entenderse a ésta dentro de la voz «fondo».

En cuanto a la clase de fondos, la ley no distingue, por lo que cualquier fuente de financiamiento cabría, fuese ilegítima o legítima. Este tópico responde así, en primer lugar, a la esencia misma del financiamiento del terrorismo como una actividad ilícita, como decíamos anteriormente, en que lo que importa es el objeto al cual es aplicado un fondo o activos, y no el origen de ellos. En segundo lugar, responde a la experiencia internacional en materia de formas de financiamiento (como además vemos en los instrumentos internacionales y en las Recomendaciones del Grupo Acción Financiera Internacional, GAFI; cf. Oficina de las Naciones Unidas contra la Droga y el Delito, 2014: 126-127), donde tales formas pueden ir, según la doctrina en Chile, desde el lavado de dinero o activos, hasta la caridad (Plaza Chávez, 2015: 173; Villegas Díaz, 2006: 23).

\section{Sujeto activo}

La expresión «el que» incluiría el sujeto activo de la conducta, que es una persona natural, por lo que el sujeto es genérico. Pero en razón de la Ley 20.393, ante la especificidad del sujeto procede también considerar a la persona jurídica, excepcionalmente, como sujeto activo del delito. Por lo que dentro de la expresión gramatical «el que», se debe considerar como sujeto activo a la persona jurídica.

El Convenio, en su artículo 2.1, usa la expresión «quien», lo cual entrega similar apertura de significados que el caso anterior, comprendiendo tanto a las personas naturales como a las jurídicas (Commonwealth Secretariat, 2002: 268).

\section{Elementos subjetivos del tipo. Dolo y culpa}

El artículo 8 de la Ley 18.314 considera un elemento subjetivo de intención trascendente en su texto: «con la finalidad de que se utilicen en la comisión de delitos [terroristas]». ${ }^{16}$ La sola inclusión de este elemento subjetivo eliminaría la posibilidad de cometer estos delitos con culpa.

16. También se usa de este modo en la legislación comparada, en el Decreto Ley 25.475 de Perú, en su artículo 4.A, cuando se señala «con la finalidad de cometer cualquiera de los delitos previstos en este decreto ley». Sobre este tema, el Convenio difiere del artículo 8 de la Ley 18.314, puesto que el Convenio utiliza las expresiones «deliberadamente» $\mathrm{y}$ «con la intención de que se utilicen, $\mathrm{o}$ a sabiendas de que serán utilizados», más bien como sinónimo de dolo. La diferencia de interpretación al darle una un sentido más restrictivo, como lo sería el artículo 8 con la integración del elemento subjetivo de intención trascedente, y el artículo 2.1 del Convenio un sentido más amplio, es porque básicamente este último está orientado hacia la cooperación internacional, por lo que la conducta que se describa tiene y debe ser lo más amplia posible para abarcar el máximo de significado de las legislaciones patrias de cada Estado, usando, gramaticalmente, el mínimo de elementos posibles. 
Esto plantea un problema probatorio similar al que ha venido ya visualizándose largamente en la doctrina chilena, respecto del delito terrorista y conforme a su elemento subjetivo expresado en el artículo 1 de la Ley 18.314, en la cláusula «cuando el hecho se cometa con la finalidad de producir en la población o en una parte de ella el temor justificado de ser víctima de delitos de la misma especie», ya que un elemento de estas características, como las del elemento subjetivo en el financiamiento del terrorismo, impide, en la generalidad de los casos, probar la finalidad (Villegas Díaz, 2016: 156-157; véase la nota al pie 76). Fuera de esto, el financiamiento del terrorismo se cometería con dolo directo.

Respecto del dolo eventual, en primer lugar, el texto no contiene alguna cláusula que indique explícita o implícitamente excluirlo y del texto no se infiere que la conducta no pueda ser cometida con dolo eventual, por lo que entendemos que no se le excluye. ${ }^{17}$

Con esta regulación se es coincidente con la generalidad de sistemas jurídicos que así lo entienden ${ }^{18}$ y se aparta de legislaciones como la australiana o la española, que castigan ciertas formas imprudentes de comisión.

\section{Concursos}

En general, habría que aplicar la regla especial del artículo 8 de la Ley 18.314, y las reglas generales existentes en el Código Penal. En el caso de la Ley 20.393, no contiene normas especiales en materia de concurso en el caso de las personas jurídicas.

La última parte del artículo 8 de la Ley 18.314, hace una referencia explícita al tema sobre concurso, ya que constituye una cláusula de subsidiariedad expresa. En efecto, señala el citado precepto que el agente será sancionado «a menos que en virtud de la provisión de fondos le quepa responsabilidad en un delito determinado, caso en el cual se le sancionará por este último título, sin perjuicio de lo dispuesto en el artículo 294 bis del Código Penal».

En primer lugar, la referencia es explícita a la conducta típica de la provisión, por lo que el «solicitar»y el «recaudar» quedan fuera de la norma reguladora del concurso.

17. Misma opinión en incluir el dolo eventual, aunque por un razonamiento distinto, de Plaza Chávez (2015: 186).

18. «No obstante, muchos sistemas jurídicos admiten también formas menos directas de intención que, al aplicarse al financiamiento del terrorismo, incluirían casos en que, por ejemplo, el perpetrador previó, pudo haber previsto, o debió haber previsto que el acto terrorista se produciría como consecuencia del suministro o la recolección de los fondos, pese a lo cual proporcionó o recolectó los fondos. En algunos países se han incluido en la legislación modalidades similares de conocimiento, y en otros puede llegarse a resultados similares a través de la aplicación de principios generales de derecho penal» (Fondo Monetario Internacional, 2003: 55). 
Esta norma fue objeto de controversia en el Congreso. Se entendió por el entonces diputado Juan Bustos Ramírez que lo que se buscaba era establecer una norma especial de absorción, para una situación que, de aplicar las reglas generales, no habría ninguna diferencia, por lo que se propuso eliminarla, siendo dicha solicitud acogida, eliminándose del articulado original (Biblioteca del Congreso Nacional, 2007: 11). En el Senado, el Ejecutivo solicitó reponerla, «no solamente por la posibilidad de una doble incriminación, sino también porque, en el caso de concurso con delitos más graves, incluida la asociación ilícita, debe castigarse por estos últimos, desechando la posibilidad de que esta nueva figura se constituya como privilegiada». Finalmente se volvió a reponer con el objeto de evitar una doble incriminación y para «evitar interpretaciones que le confieran a la figura que se crea el carácter de un tipo privilegiado, que redundaría en una disminución de la sanción de quienes actúan como autores o cómplices mediante el financiamiento de un delito terrorista. De esta forma se reserva el nuevo tipo penal exclusivamente, a los casos en que el financiamiento no va acompañado del principio de ejecución del delito terrorista específico que se pretende apoyar» (Biblioteca del Congreso Nacional, 2007: 30). Siendo así, se repuso lo eliminado en el primer trámite constitucional. La Cámara de Diputados, en tercer trámite constitucional, rechazó en forma unánime esta modificación del Senado. Bustos argumentó que se producía con esta reposición un problema jurídico, puesto que habría una mala solución de los concursos ideales, produciendo problemas de impunidad, debiendo dejarlo a las reglas generales que incluso cubren más situaciones, que con la cláusula original del Ejecutivo. Conforme a ello, se rechazó la modificación, habiendo de resolverse en Comisión Mixta (Biblioteca del Congreso Nacional, 2007: 42). En ésta se resolvió mantener la reposición hecha por el Senado (Biblioteca del Congreso Nacional, 2007: 48).

No manifestaremos nuestra opinión sobre si debiese o no haberse suprimido la cláusula de subsidiariedad, dado que dicha cláusula es una realidad normativa en el texto positivo. Más bien, se expresarán los argumentos vertidos en dichas discusiones que exigían la necesidad de su incorporación.

Básicamente estos argumentos eran, que con la existencia de la cláusula (Congreso Nacional, 2003b: 7-8):

- Se evitaba una doble incriminación.

- Se resolvía un eventual concurso aparente de leyes penales, en casos como en los que exista provisión de fondos, y participación en el delito terrorista que se financia.

- Para no confundirse con los casos de los delitos de asociación ilícita para cometer actos terroristas (artículos 2, número 5 y 3 inciso 4, Ley 18.314) y donde se penan conforme al castigo por el delito de asociación ilícita de miembros 
sin el rol de dirección y del de suministro de medios a una asociación ilícita (artículo 294 del Código Penal), esto es, la pena para dichos delitos aumentada en un grado.

- Para no ser interpretada como una figura privilegiada del delito de asociación ilícita o de las formas de participación en otro delito terrorista de lesión.

En estos casos previamente expuestos habría que tener en consideración al juzgador, en el evento de producirse una situación como la descrita en ellos. De ahí que, y conforme a la cláusula de subsidiariedad, solo sería castigada como delito la conducta de provisión, siempre y cuando no constituya a la vez otro delito, ya que, en este último caso, se castigará por este último delito.

Cuando el provisionista además cometa el delito de asociación ilícita terrorista (artículo 2 número 5 de la Ley 18.314), habrá de producirse un concurso ideal entre ambos delitos, debiendo aplicarse el artículo 74 del Código Penal. Así lo ha entendido parte de la doctrina nacional (Plaza Chávez, 2015: 182).

\section{Penas}

Si actuaren personas naturales, habrá de aplicarse la sanción establecida en el artículo 8 de la Ley 18.314, conforme al cual se aplicaría una "pena de presidio menor en su grado medio a presidio mayor en su grado mínimo».

En materia de penas, se aplicarían los artículos 8 a 13 de la Ley 20.393, penas especiales para las personas jurídicas, según sea el caso, esto es, la «disolución de la persona jurídica o cancelación de la personalidad jurídica», la "prohibición temporal o perpetua de celebrar actos y contratos con los organismos del Estado», "pérdida parcial o total de beneficios fiscales o prohibición absoluta de recepción de los mismos por un período determinado», «multa a beneficio fiscal», $\mathrm{y}$ «las penas accesorias previstas en el artículo 13», y, entre estas últimas, la que mayor relevancia tendría frente al delito de financiamiento el terrorismo habría de ser el comiso.

\section{Normas de aplicación general}

Fuera del obvio capítulo 2 de la Ley 18.314, que se refiere a las disposiciones de tipo procesal, la Ley citada contiene algunas normas de aplicación general y, por ende, aplicables al delito de financiamiento terrorista.

Así, es posible aplicar la norma contenida en el artículo 4, sobre atenuación de la pena, según la cual se disminuye hasta en dos grados la pena:

Respecto de quienes llevaren a cabo acciones tendientes directamente a evitar o aminorar las consecuencias del hecho incriminado, o dieren informaciones o proporcionaren antecedentes que sirvieren efectivamente para impedir o prevenir la 
perpetración de otros delitos terroristas, o bien, para detener o individualizar a responsables de esta clase de delitos.

Respecto de las personas naturales, se aplicarían las normas generales contenidas en el Código Penal.

En el caso de las personas jurídicas y fuera de la norma anterior sobre circunstancias modificatorias de la responsabilidad penal, se aplicarían las normas generales que procedan que prescriben los artículos 6 y 7 de la Ley 20.393.

Tratándose de la norma sobre inhabilidades del artículo 9 de la Constitución, que se hace aplicable a los condenados por los delitos establecidos en el artículo 1 y 2 de la Ley 18.314, conforme al artículo 5 de la misma ley, no sería aplicable al delito de financiamiento del terrorismo, desde que esta norma sólo es procedente para los delitos del artículos 1 y 2 en específico, y no lo extiende a otros delitos, ni puede entenderse tampoco por interpretación extensiva, en razón de la taxatividad. Por lo que se aplican, en este caso, las reglas generales contenidas en el Código Penal sobre inhabilidad.

\section{Referencias}

Biblioteca del Congreso Nacional de Chile (2007). Historia de la Ley 19.906. MODIFICA LA LEY 18.314, sobre conductas terroristas, en orden a sancionar más eficazmente la financiación del terrorismo, en conformidad a lo dispuesto por el Convenio Internacional para la Represión de la Financiación del Terrorismo. Disponible en http://bit.ly/2tnfuVI.

- . (2017). Historia de la Ley 20.393. Establece la responsabilidad penal de las personas jurídicas en los delitos de lavado de activos, financiamiento del terrorismo y delitos de cohecho que indica, Valparaíso. Disponible en http://bit.ly/2rVjw7v.

BInding, Karl (1918). Die Normen Und Ihre Übertretung: Eine Untersuchung Über Die Rechtmässige Handlung Und Die Arten Des Delikts. Vol. I y II. Leipzig: Felix Meiner.

Commonwealth SeCretariat (2002). Implementation kits for the international counter-terrorism conventions. Londres. Disponible en https://www.unodc.org/tldb/ pdf/commonwealth_manual.pdf

-. (2006). Implementation kits for the international counter-terrorism conventions. Practice and procedures. Londres. Disponible en https://www.unodc.org/tldb/pdf/ CT_manual_commonwealth.pdf

Congreso Nacional de Chile (2001). Boletín 2799-10. Aprueba el Convenio Internacional para la Represión de la Financiación del Terrorismo, adoptado en Nueva York, el 9 de diciembre de 1999. Disponible en http://bit.ly/2rGjMDd.

Fondo Monetario InTERnACIONAL (2003). Represión del financiamiento del terrorismo. Manual para la redacción de leyes. Disponible en http://bit.ly/2rGQNiX. 
GaEte GonzÁlez, Eugenio Alberto (2010). «La tipificación jurídica del terrorismo». Revista de Derecho (Pontificia Universidad Católica de Valparaíso), 23: 451-46o. Disponible en http://bit.ly/2txTrsp.

González CussaC, José Luis y Caty Vidales RodríGuez (2009). «El nuevo delito de financiación del terrorismo: Consideraciones acerca de su necesidad y conveniencia». En José Luis González Cussac (editor), Financiación del terrorismo, blanqueo de capitales y secreto bancario: Un análisis crítico (pp. 181-197). Valencia: Tirant Lo Blanch.

Hiller, Carl (1880). «Ueber den gegenwärtigen Stand der Lehre von der Concurrenz der Delicte». En GerichtsSaal, 32: 195-240.

Lamarca Pérez, Carmen (2013). «Noción de terrorismo y clases. Evolución legislativa y político-criminal». En Juanatey Dorado, Carmen y Fernández-Pacheco Estrada, Cristina (editoras), El nuevo panorama del terrorismo en España: Perspectiva penal, penitenciaria y social (pp. 39-48). Alicante: Universidad de Alicante.

LeIva, Melany Cruz (2015). «Re-pensar el concepto de terrorismo: Un discusión político-histórica». Apuntes de Investigación del CECYP, 26: 179-189.

López CALERA, Nicolás María (2002). «El concepto de terrorismo: ¿Qué terrorismo? ¿Por qué el terrorismo? ¿Hasta cuándo el terrorismo?». Anuario de Filosofía del Derecho, 19: 51-71.

Nievas, Flabián (2015). «Terrorismo: En búsqueda del concepto». Cuadernos de Marte, 9: 173-202.

Oficina de las Naciones Unidas contra la Droga y el Delito (2006). Prevención de los actos terroristas: Estrategia de justicia penal que incorpora las normas del estado de derecho en la aplicación de los instrumentos de las Naciones Unidas relativos a la lucha contra el terrorismo. Viena, Nueva York: ONU. Disponible en http://bit.ly/2t2PDzF.

-. (2014): Guía para Colombia sobre el régimen jurídico contra el terrorismo y su financiación. Disponible en http://bit.ly/2sYFojY.

Passas, Nikos y Andrea Giménez-Salinas Framis (2007). «La financiación del terrorismo de Al Qaida: Mitos y realidades». Revista de Derecho Penal y Criminología, 19: 493-521.

Plaza Chávez, Ignacio Javier (2015). «Análisis dogmático-penal del delito de financiamiento del terrorismo». Revista de Estudios de la Justicia, 20: 171-194.

Rivas Nieto, Pedro (2013). Terrorismo y antiterrorismo en el mundo contemporáneo. Debate: Buenos Aires.

Rodríguez Morales, Tania Gabriela (2012). «El terrorismo y nuevas formas de terrorismo». Espacios Públicos, 15: 72-95.

Torres VÁsquez, Henry (2010). «El concepto de terrorismo, su inexistencia o inoperancia: la apertura a la violación de Derechos Humanos». Diálogos de Saberes: Investigaciones y Ciencias Sociales, 32: pp. 77-90. 
ÚbedA-Portugués, José Escribano (2008). El terrorismo ante el derecho internacional público. Madrid: Liber Factory.

Villegas Díaz, Myrna (2006). «Los delitos de terrorismo en el Anteproyecto de Código Penal». Política Criminal, 2: 1-31.

-. (2016). «Contribuciones para un concepto de terrorismo en el derecho penal chileno». Política Criminal, 11: 140-172.

Waldmann, Peter (2007). Guerra civil, terrorismo y anomia social: El caso colombiano en un contexto globalizado. Bogotá: Norma.

ZaLAquetT, José (2006). «Chile ratifica la Convención Interamericana contra el Terrorismo». Anuario de Derechos Humanos, 2: 179-184.

\section{Sobre el autor}

Edison Carrasco Jiménez es doctor en Derecho Penal, profesor e investigador en la Universidad Andrés Bello, sede Concepción. Su correo electrónico es edison.carrasco@unab.cl. 